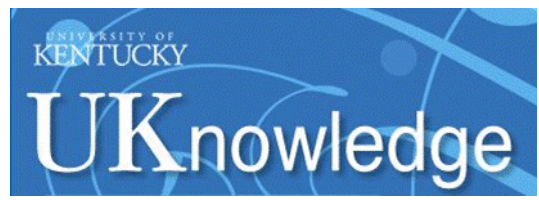

University of Kentucky

UKnowledge

Power and Energy Institute of Kentucky Faculty Publications

$10-9-2020$

\title{
Design Optimization and Comparison of Direct-Drive Outer-Rotor SRMs Based on Fast Current Profile Estimation and Transient FEA
}

\author{
Vandana Rallabandi \\ University of Kentucky, vandana.rallabandi@uky.edu \\ Peng Han \\ University of Kentucky, peng.han@uky.edu \\ Jie $\mathrm{Wu}$ \\ Zhengzhou University of Light Industry, China
}

Aaron M. Cramer

University of Kentucky, aaron.cramer@uky.edu

Dan M. Ionel

University of Kentucky, dan.ionel@uky.edu

See next page for additional authors

Follow this and additional works at: https://uknowledge.uky.edu/peik_facpub

Part of the Power and Energy Commons

Right click to open a feedback form in a new tab to let us know how this document benefits you.

\section{Repository Citation}

Rallabandi, Vandana; Han, Peng; Wu, Jie; Cramer, Aaron M.; Ionel, Dan M.; and Zhou, Ping, "Design Optimization and Comparison of Direct-Drive Outer-Rotor SRMs Based on Fast Current Profile Estimation and Transient FEA" (2020). Power and Energy Institute of Kentucky Faculty Publications. 61.

https://uknowledge.uky.edu/peik_facpub/61

This Article is brought to you for free and open access by the Power and Energy Institute of Kentucky at UKnowledge. It has been accepted for inclusion in Power and Energy Institute of Kentucky Faculty Publications by an authorized administrator of UKnowledge. For more information, please contact UKnowledge@lsv.uky.edu. 


\title{
Design Optimization and Comparison of Direct-Drive Outer-Rotor SRMs Based on Fast Current Profile Estimation and Transient FEA
}

\author{
Digital Object Identifier (DOI) \\ https://doi.org/10.1109/TIA.2020.3029995
}

\section{Notes/Citation Information}

Published in IEEE Transactions on Industry Applications, v. 57, issue 1.

(C) 2020 IEEE Copyright Notice. "Personal use of this material is permitted. Permission from IEEE must be obtained for all other uses, in any current or future media, including reprinting/republishing this material for advertising or promotional purposes, creating new collective works, for resale or redistribution to servers or lists, or reuse of any copyrighted component of this work in other works."

The document available for download is the authors' manuscript version. The final published version is copyrighted by IEEE and is available as: V. Rallabandi, P. Han, J. Wu, A.M. Cramer, D.M. Ionel, and P. Zhou, "Design Optimization and Comparison of Direct-drive Outer-rotor SRMs Based on Fast Current Profile Estimation and Transient FEA," in IEEE Transactions on Industry Applications, doi: 10.1109/ TIA.2020.3029995

Authors

Vandana Rallabandi, Peng Han, Jie Wu, Aaron M. Cramer, Dan M. Ionel, and Ping Zhou 


\title{
Design Optimization and Comparison of Direct-drive Outer-rotor SRMs Based on Fast Current Profile Estimation and Transient FEA
}

\author{
Vandana Rallabandi, Senior Member, IEEE, Peng Han, Senior Member, IEEE, Jie Wu, Member, IEEE, \\ Aaron M. Cramer, Senior Member, IEEE, Dan M. Ionel, Fellow, IEEE, and Ping Zhou, Fellow, IEEE
}

\begin{abstract}
Outer-rotor switched reluctance machines (SRMs) have drawn much attention as promising candidates for in-wheel direct-drive motors of future electric vehicles. This paper presents a systematic performance comparison of three outer-rotor SRM topologies for in-wheel traction applications in terms of the specific torque, electromagnetic efficiency, torque ripple, radial force and mechanical aspects. A generalized design optimization framework for SRMs is proposed to enable the fast evaluation of large numbers of designs generated from the differential evolution (DE) by incorporating an analytical current profile estimation into the transient finite element analysis (FEA). The relationship between the saliency ratio and converter volt-ampere (VA) rating is also discussed. The calculations are then benchmarked with the experimental results from an existing prototype. The effectiveness of the performance prediction method and the proposed optimization approach is validated.
\end{abstract}

Index Terms-Converter VA rating, current profile, differential evolution, direct-drive, in-wheel motor, optimization, segmented rotor, switched reluctance machine.

\section{NOMENCLATURE}

$D_{\text {ri }}, D_{\text {ro }}$

$D_{s h}$

$h_{r t t}, h_{s t t}$

$h_{r y}, h_{s y}$

$\theta$

$\theta_{\text {on }}, \theta_{\text {off }}$

$\theta_{\text {rise }}, \theta_{\text {fall }}$

$\theta_{r t}, \theta_{s t}$

$\theta_{r t t}, \theta_{\text {stt }}$

$I_{p}, i$

$k_{b y}$

$k_{r y}$

$k_{r p a 1}, k_{r p a 2}$

$k_{r t}, k_{s t}$
Inner and outer diameter of rotor, respectively.

Shaft diameter.

Thickness of rotor and stator tooth tip, respectively.

Rotor and stator yoke thickness, respectively.

Angular position of rotor.

Turn-on and turn-off angle in electrical degrees, respectively.

Rising and falling time represented by electrical degrees, respectively.

Rotor and stator tooth arc, respectively.

Rotor and stator tooth tip arc, respectively.

Rated phase current (peak value) and phase current, respectively.

Ratio of stator yoke thickness to stator outer radius.

Ratio of rotor yoke thickness to rotor thickness in radial direction.

Ratio of rotor pole arc at rotor inner diameter to rotor pole pitch.

Ratio of real rotor tooth arc and real stator tooth arc to their maximum values, respectively.$$
k_{t i p 1}, k_{t i p 2}
$$$$
k_{w t i p 1}, k_{w t i p 2}
$$

$d c$

$$
\begin{aligned}
& k_{r t t}, k_{s t t} \\
& k_{s} \\
& k_{s 1}, k_{s 2} \\
& k_{s p a} \\
& k_{s y} \\
& k_{t i p 1}, k_{t i p} 2 \\
& k_{w t i p 1}, k_{u t} \\
& L_{,} R \\
& L_{a}, L_{u} \\
& m \\
& N_{r}, N_{s} \\
& V \\
& V_{d c} \\
& \omega
\end{aligned}
$$

Ratio of real rotor tooth tip arc and real stator tooth tip arc to their maximum values, respectively.

Split ratio, i.e., ratio of rotor inner diameter to rotor outer diameter.

Ratio of stator main tooth width and stator auxiliary tooth width to stator pole pitch, respectively.

Ratio of stator pole arc to stator pole pitch. Ratio of stator yoke thickness to stator thickness in radial direction.

Ratio of stator main tooth tip depth and stator auxiliary tooth tip depth to stator outer radius, respectively.

Ratio of stator main tooth tip width and stator auxiliary tooth tip width to stator pole pitch, respectively.

Phase inductance and resistance.

Aligned and unaligned inductance, respectively.

Number of phase.

Number of rotor poles and stator teeth, respectively.

Terminal voltage.

Dc bus voltage.

Angular speed of rotor.

\section{INTRODUCTION}

Switched reluctance machines (SRMs) are attractive candidates for traction motors of future electric and hybrid vehicles, owing to the rugged construction, relatively high specific torque and efficiency, and inherent fault-tolerant capability [1-3]. The emerging in-wheel direct-drive technology in the automobile industry may further open up new opportunities for SRMs considering their robustness to harsh operational conditions [4].

Outer-rotor configurations are more appealing for in-wheel traction applications, because they facilitate direct coupling to the wheel rim thereby simplifying mechanical transmission. In addition, the increased torque capability due to a higher airgap diameter, and larger rotor inertia, help to dampen the torque ripple and provide smooth and stable operation, even at low speeds.

The design optimization of SRMs is challenging. The evaluation of each design involves intensive computation consid- 
ering the strong non-linearity introduced by magnetic saturation [5]. In addition, Maxwell's equations have to be solved together with those for external driving circuits to consider the irregular current waveforms, which depend on the on/off state of switches in each time step, especially when current chopping control is used. As a result, the evaluation time of each single design is increased significantly and it becomes impractical to conduct large-scale design optimization and systematic performance comparisons between different SRM topologies.

To simplify the optimization problem and to reduce the computation time, analytical magnetic equivalent circuit models or surrogate models were commonly used [6, 7]. Optimizing the static torque instead of the more desired average torque was also adopted to accelerate the optimization process $[8,9]$.

Most of the existing work on design optimization of SRMs focuses on design space reduction by decreasing the number of design variables. For instance, a conventional 12-slot 8-pole (12s8p) SRM was designed to achieve a predefined torquespeed envelope for electric vehicles and compared with interior permanent magnet and induction motors [10]. In another work, three design variables, i.e., the number of turns, turn-on and turn-off angles were considered, but only the turn-on and turn-off angles were optimized using multiobjective genetic algorithm to maximize the average torque and minimize the torque ripple for each specific design [11]. The design of experiments method and sensitivity analysis were applied to the design optimization of SRMs to identify the less significant variables and narrow down the search space [7, 12].

Reducing the number of independent variables can significantly reduce the computational burden but it is not always possible. When all the design variables have significant impacts on the objective functions, it becomes necessary to reduce the computation time of each FEA evaluation. In order to minimize the computation time for each design, the required current excitation for solving the magnetic field is determined prior to the transient FEA. An inductance approximation method based on Fourier series and magnetostatic FEA was used to construct the current profile and optimize the torque waveform for a 6-slot 4-pole SRM [13], yet the magnetic saturation was not considered. An $80-\mathrm{kW}$ segmented rotor SRM was optimized based on a combination of magnetostatic and transient FEA, where the current excitation profile was estimated from the peak static torque by introducing a few empirical coefficients, which reduces its universality [14].

The multiobjective optimization and electromagnetic performance comparison of three typical outer-rotor SRM topologies have been presented in [15] based on simplified trapezoidal current waveforms. This paper enhances the published conference paper by generalizing the proposed design optimization framework to include more accurate current excitation taking into account the influence of the hysteresis current regulation and the magnetic saturation of phase inductance. An analytical current profile estimation method is proposed to reduce the evaluation time per design without reducing the number of independent variables. The aligned and unaligned inductance information obtained from magnetostatic FEA is used to determine the current excitation profile before the transient magnetic field solver is called, which enables the computation acceleration achieve by the time decomposition method (TDM) [16, 17]. In addition, the definition and calculation of volt-ampere (VA) rating and power factor in SRMs are provided to fill the gap in existing literature on the optimal design of SRMs, considering the fact that the specific torque and converter VA rating are conflicting objectives [18].

This paper is organized as follows. Section II reviews the electromagnetic design considerations of SRMs for in-wheel direct-drive applications. Section III presents the proposed design optimization framework based on fast current profile estimation and multiobjective differential evolution (DE) algorithm. The optimization results are reported and discussed in Section IV, followed by the FE and experimental validation detailed in Section V. Section VI concludes the full paper.

\section{Electromagnetic Design CONSIDERATIONS FOR IN-WHEEL SRMS}

The direct-drive designs in this paper are intended for in-wheel electric and hybrid vehicles, and therefore employ external rotor constructions facilitating direct integration into the wheel. The rotor outer diameter $D_{\text {or }}$ and shaft diameter $D_{s h}$ are constrained by the wheel rim and shaft, respectively. The speed is relatively low, which is determined by the maximum vehicle speed and wheel outer diameter. Based on the available space in a 10 inch wheel, specifications of the design example are determined, as tabulated in Table I.

\section{A. Available Topologies}

Aside from the conventional SRM topologies with tooth wound coils and weak mutual coupling between phases, quite a few topological variations of SRMs have emerged in the past decade, such as those with more rotor poles than stator teeth [19], with magnetically disconnected rotor segments [14, 20], with split stator teeth [21], with segmented stator [22] and the mutually-coupled type $[23,24]$. In general, the number of teeth and rotor poles in SRMs are constrained by $[25,26]$

$$
\begin{aligned}
& \operatorname{LCM}\left(N_{r}, N\right)=m N_{r}, \\
& \begin{cases}N=N_{s}, & \text { without auxiliary teeth, } \\
N=\frac{1}{2} N_{s}, & \text { with auxiliary teeth, }\end{cases}
\end{aligned}
$$

where $L C M$ is the least common multiple. $N_{s}$ and $N_{r}$ are the number of stator teeth and rotor poles, respectively. $m$ is the number of phase. Three candidate SRMs are considered for the targeted application, i.e., a 12-slot 26-pole (12s26p) SRM, a 6-slot 10-pole (6s10p) SRM, and a 12s8p SRM, as shown in Fig. 1. The flux lines and flux density maps of the studied machine topologies at unaligned and aligned positions are also included.

Table I: Design Specifications.

\begin{tabular}{lr}
\hline Parameters & Value \\
\hline Rated torque $(\mathrm{Nm})$ & 18 at $600 \mathrm{rpm}$ \\
Current density $\left(\mathrm{A} / \mathrm{mm}^{2}\right)$ & $\leq 5$ \\
DC bus voltage $(\mathrm{V})$ & 200 \\
Shaft diameter/airgap lengh $(\mathrm{mm})$ & $20 / 0.4$ \\
Outer diameter/axial length $(\mathrm{mm})$ & $\leq 240 / 40$ \\
\hline
\end{tabular}




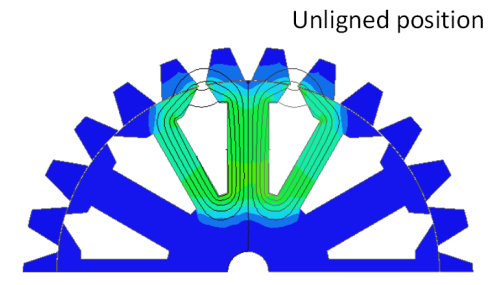

Aligned position

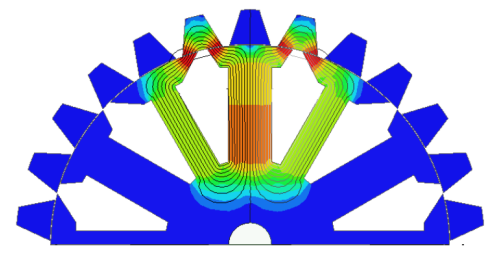

(a)
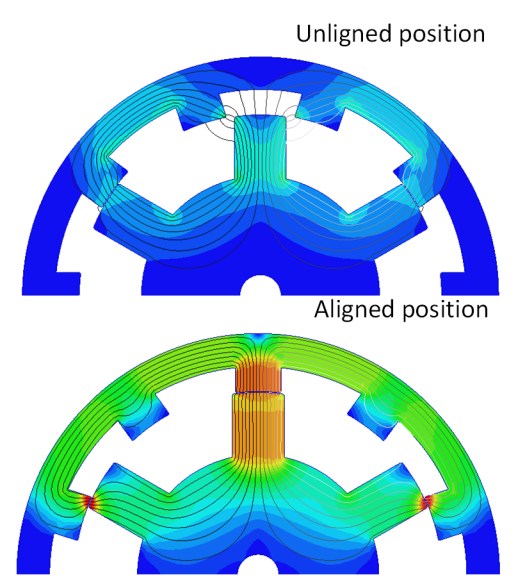

(b)

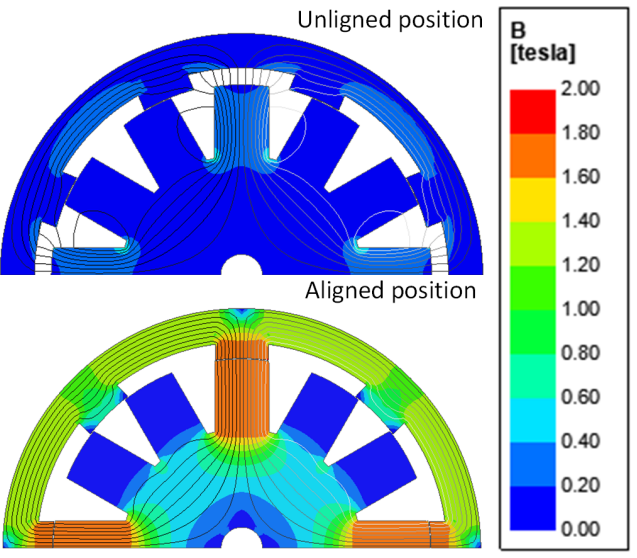

(c)

Fig. 1. Flux lines and flux density maps for example designs of the selected outer-rotor SRM topologies at unaligned and aligned positions: (a) 12s26p SRM, (b) 6s10p SRM and,(c) 12s8p SRM. The three SRMs have the same current density $4 \mathrm{~A} / \mathrm{mm}^{2}$ and same dimensions: total outer diameter of rotor $=232 \mathrm{~mm}$, shaft diameter $=20 \mathrm{~mm}$, airgap length $=0.4 \mathrm{~mm}$ and stack length $=40 \mathrm{~mm}$.

In the 12s26p SRM, only the alternate stator teeth are wound with concentrated coils. The teeth which are not wound simply serve as returning paths for the flux, and are narrower than the main teeth with coils.

\section{B. Mode of Operation}

SRMs can be operated in the constant torque mode at low speeds with current chopping control, constant power mode at medium speeds with angular position control and the natural mode at high speeds. Current waveforms vary significantly with the modes of operation and typical current waveforms for different modes of operation have been well illustrated in [27]. The current profile has a significant impact on the average torque and torque ripple, depending on the harmonic contents [28]. For in-wheel direct-drive applications, the rotor speed is relatively low and therefore, the current chopping control with fixed turn-on and dwell angles is employed. The block diagram for the closed-loop speed control of SRMs under study is shown in Fig. 2.

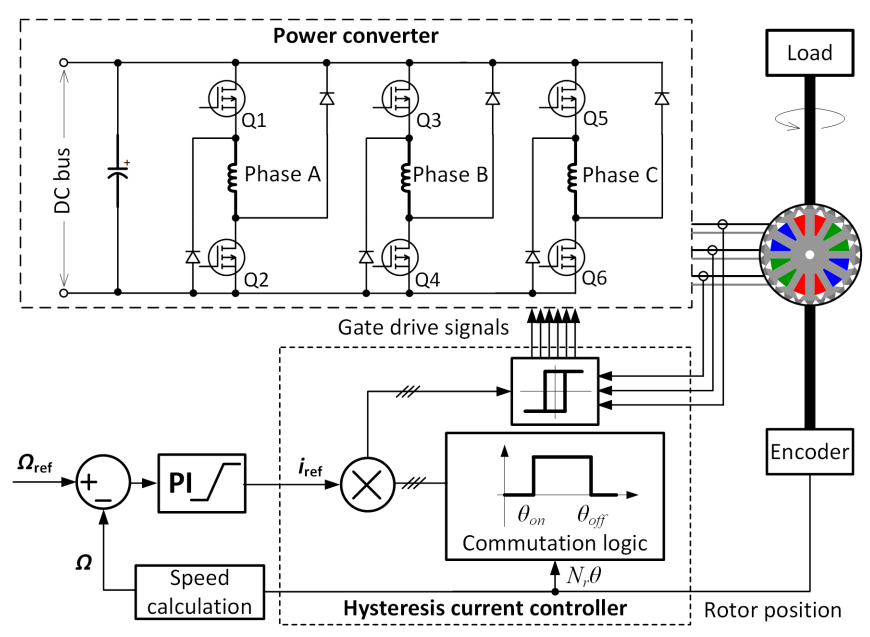

Fig. 2. Closed-loop speed control block diagram for SRMs under study.

\section{Design Optimization based on Current Profile Estimation And Multiobjective DE}

\section{A. Current Profile Estimation}

In order to estimate the current profile, specifically, the rising and falling times, that can be used for the performance evaluation with transient FEA, the inductance information is required. However, the inductance is dependent on the instantaneous winding current and rotor position, as shown by the unaligned and aligned inductances at different current levels of the three selected topologies in Fig. 3.

To simplify the analysis, the inductance at a given current is assumed to vary sinusoidally with the rotor position. In the unsaturated condition, the inductance is a function of the rotor position and independent of the winding current. The current profile can be readily solved from:

$$
\begin{aligned}
V & =i R+L(i, \theta) \frac{d i}{d t}+i \frac{d L(i, \theta)}{d \theta} \omega \\
& = \begin{cases}V_{d c}, & \theta_{\text {on }}<\theta \leq \theta_{\text {on }}+\theta_{\text {rise }}, \\
-V_{d c}, & \theta_{\text {off }}<\theta \leq \theta_{\text {off }}+\theta_{\text {fall }},\end{cases}
\end{aligned}
$$

where $V$ is the terminal voltage of phase winding, $i$ the phase current, $R$ the phase resistance, $L$ the phase inductance, $\theta$ the

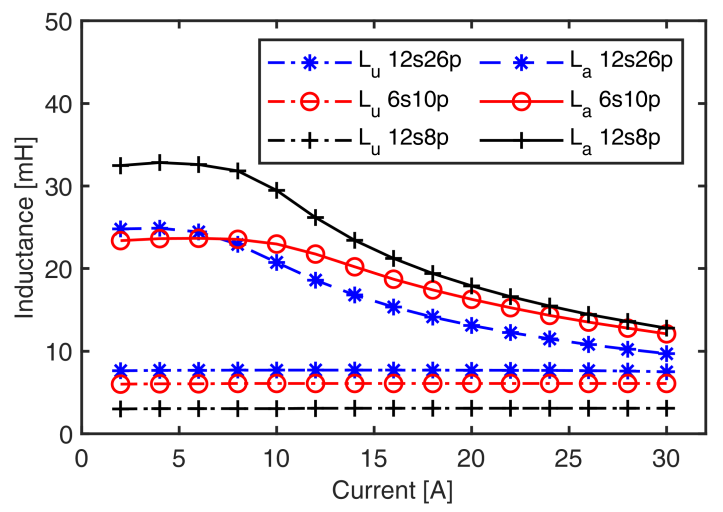

Fig. 3. Typical inductance characteristics of SRMs under study at unaligned and aligned positions. 


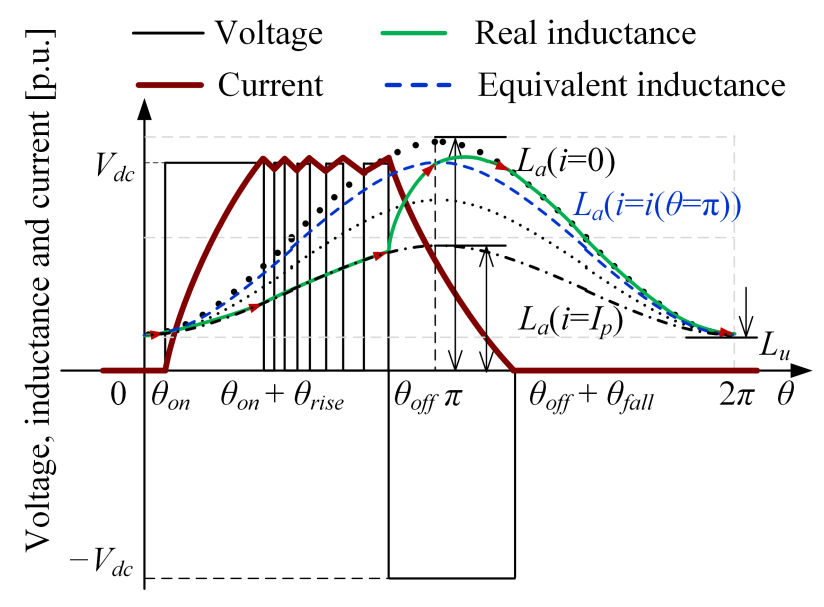

Fig. 4. Schematic diagram for current profile derivation.

rotor position in electrical degrees, $\omega$ the corresponding rotor angular speed.

With saturation, the inductance waveform in a full electrical cycle is distorted, as shown by the solid green line in Fig. 4. From $\theta_{o n}$ to $\theta_{\text {off }}$, the inductance can be approximated by that at $i=I_{p}$, i.e., the black dash-dotted line. Between $\theta_{o f f}$ and $\theta_{\text {off }}+\theta_{\text {fall }}$, the inductance sees a dramatic change due to the current decrease. The inductance from $\theta_{\text {off }}+\theta_{\text {fall }}$ to $2 \pi$ is that at $i=0$, i.e., the black dotted line since the current is zero. A simple equivalent inductance denoted by the dashed blue line is used to approximate the inductance profile between $\theta_{\text {off }}$ and $2 \pi$. The phase inductance can therefore be written as:

$$
\begin{aligned}
& L(i, \theta)=A+B \cos \theta \\
& \begin{cases}\frac{L_{u}+L_{a}\left(I_{p}\right)}{2}+\frac{L_{u}-L_{a}\left(I_{p}\right)}{2} \cos \theta, & \theta_{\text {on }}<\theta \leq \theta_{\text {off }} . \\
\frac{L_{u}+L_{a}(i(\theta=\pi))}{2}+\frac{L_{u}-L_{a}(i(\theta=\pi))}{2} \cos \theta, & \theta_{\text {off }}<\theta \leq 2 \pi .\end{cases}
\end{aligned}
$$

Neglecting the winding resistance and substituting (3) into (2) yields:

$$
V=(A+B \cos \theta) \frac{d i}{d t}-i B \omega \sin \theta
$$

Considering $t=\theta / \omega$,

the voltage equation (4) can be simplified to:

$$
\frac{V}{\omega}=(A+B \cos \theta) \frac{d i}{d \theta}-i B \sin \theta .
$$

The current rising and falling profiles can be fitted by quadratic formulas based on the following:

$$
\begin{aligned}
& \left\{\begin{array}{l}
\left.i\right|_{\theta=\theta_{o n}}=0 \\
\left.\frac{d i}{d \theta}\right|_{\theta=\theta_{o n}}=\frac{\frac{V_{d c}}{\omega}}{A+B \cos \theta_{o n}} \\
\left.i\right|_{\theta=\theta_{o n}+\theta_{\text {rise }}}=I_{p} \\
\left.\frac{d i}{d \theta}\right|_{\theta=\theta_{o n}+\theta_{\text {rise }}}=\frac{\frac{V_{d c}}{\omega}+B I_{p} \sin \left(\theta_{o n}+\theta_{\text {rise }}\right)}{A+B \cos \left(\theta_{o n}+\theta_{\text {rise }}\right)},
\end{array}\right. \\
& \left\{\begin{array}{l}
\left.i\right|_{\theta=\theta_{o f f}}=I_{p} \\
\left.\frac{d i}{d \theta}\right|_{\theta=\theta_{o f f}}=\frac{-\frac{V_{d c}}{\omega}+B I_{p} \sin \theta_{o f f}}{A+B \cos \theta_{o f f}} \\
\left.i\right|_{\theta=\theta_{o f f}+\theta_{f a l l}}=0 \\
\left.\frac{d i}{d \theta}\right|_{\theta=\theta_{o f f}+\theta_{\text {fall }}}=\frac{-\frac{V_{d c}}{\omega}}{A+B \cos \left(\theta_{o f f}+\theta_{\text {fall }}\right)}
\end{array}\right.
\end{aligned}
$$

The rising time, represented by angle $\theta_{o n}$, is:

$$
\theta_{\text {rise }}=\frac{2 I_{p}}{\frac{\frac{V_{d c}}{\omega}+B I_{p} \sin \left(\theta_{\text {on }}+\theta_{\text {rise }}\right)}{A+B \cos \left(\theta_{\text {on }}+\theta_{\text {rise }}\right)}+\frac{\frac{V_{d c}}{\omega}}{A+B \cos \theta_{\text {on }}}} .
$$

Similarly, the falling time is:

$$
\theta_{\text {fall }}=\frac{2 I_{p}}{\frac{\frac{V_{d c}}{\omega}-B I_{p} \sin \theta_{o f f}}{A+B \cos \theta_{o f f}}+\frac{\frac{V_{d c}}{\omega}}{A+B \cos \left(\theta_{o f f}+\theta_{f a l l}\right)}} .
$$

Once $\theta_{o n}$ and $\theta_{o f f}$ are given, $\theta_{\text {rise }}$ and $\theta_{\text {fall }}$ can be determined by (8) and (9) and the current profile corresponding to a specified dc bus voltage can be constructed for each design based on the determination of aligned and unaligned inductances from magnetostatic simulations. The current profile is then stored in a lookup table and used as the excitation for transient FEA. The current profile can be as simple as a trapezoidal waveform or can include more details in the current rising and falling periods.

The proposed current profiling estimation is verified by transient FE calculations with voltage source excitation. Current source 1 employs the simplified trapezoidal current waveform and current source 2 uses a more detailed piece-wise linear current waveform whose slopes at $\theta_{\text {on }}, \theta_{\text {on }}+\theta_{\text {rise }}, \theta_{\text {off }}$ and $\theta_{\text {off }}+\theta_{\text {fall }}$ are the same as those of the real current profile, as shown in Fig. 5.

Current source 2 provides a very good approximation for the accurate current waveform from voltage source excitation in
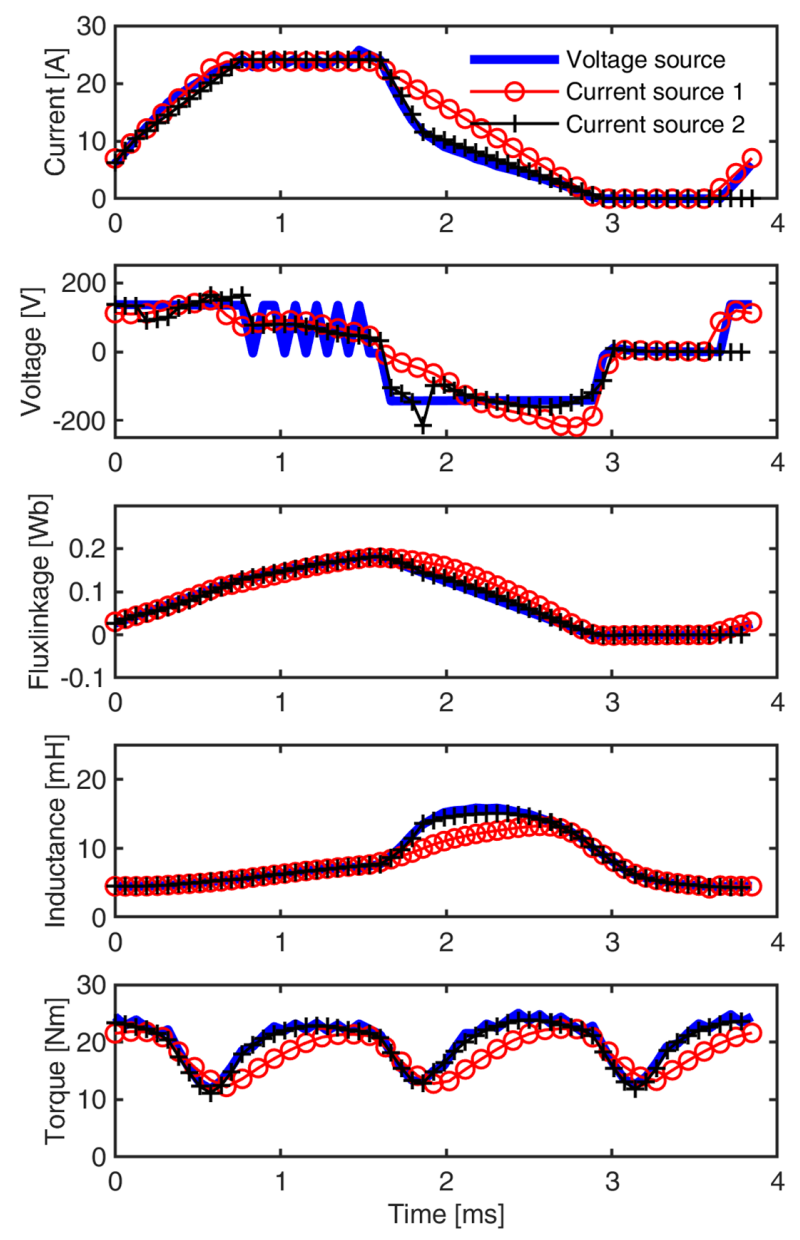

Fig. 5. FE results using current source and voltage source excitations 
general, except at the peak current interval, where the current is chopped to achieve the rated current. Current source 1 produces some deviations in the current falling period, which causes some differences in instantaneous flux linkage, terminal voltage and torque. For simplicity, current source 1 is used in the optimization studies.

It can be seen that $\theta_{\text {rise }}$ is related to the dc bus voltage, rated current, supply frequency and inductance profiles. The $12 \mathrm{~s} 26 \mathrm{p}$ SRM has the highest unaligned inductance and therefore the longest rising time. A higher dc bus voltage will accelerate the rise of the current, but it also increases the converter VA rating. The converter VA rating used in this paper is defined as the product of the peak current and peak voltage in each switch, considering that the ratio between peak current and rms current is difficult to define and it can vary between wide limits depending on the control strategy and the electromagnetic design of the motor. The rms phase current typically lies between 0.3 and 0.5 times the peak current according to [18].

\section{B. Optimization Framework}

The proposed optimization framework based on the current profile estimation is illustrated in Fig. 6. The current profiles constructed from (8) and (9) for the three selected topologies shown in Fig. 1 are illustrated in Fig. 7. It can be seen that the $12 \mathrm{~s} 8 \mathrm{p}$ has the shortest rising and falling time among the three SRMs. The 12s26p SRM has the longest rising and falling time due to its large unaligned inductance and small saliency ratio, which is defined as the ratio between the aligned inductance at the rated current and the unaligned inductance.

\section{Optimization Implementation}

The total electromagnetic loss and total active mass are the two objectives considered in this study. All the studied machine designs produce the same target torque of $18 \mathrm{Nm}$ at $600 \mathrm{r} / \mathrm{min}$, and have the same outer diameter $232 \mathrm{~mm}$, airgap length $0.4 \mathrm{~mm}$ and number of turns per phase 200 . The input variables considered in the optimization are geometric parameters, whose ranges and values for the reference designs are tabulated in Table II. The geometric parameters are illustrated in Fig. 8. The ranges for the variables are initially determined by varying values for the reference design by a certain percentage, $\pm 20 \%$, in this study, and changed iteratively according to the distributions of variables for Pareto front designs. In $12 \mathrm{~s} 8 \mathrm{p}$ and $6 \mathrm{~s} 10 \mathrm{p}$ SRMs, 7 independent geometric variables are considered, and the 12s26p SRM has 11 variables.

With the constructed current profiles, two-dimensional (2D) FE models with current source excitations are developed. In addition to the total electromagnetic loss and total active mass, the torque ripple, radial force and mechanical aspects, converter VA rating and saliency ratio are also evaluated. The evaluation of the core losses require at least two electrical cycles, and the TDM within ANSYS Maxwell, which permits the parallel computing of multiple time steps is employed to speed up the calculation [16]. The TDM method can be applied to SRMs and produce the same results compared with the non-TDM as long as the excitation applied to the FE model is independent of the simulation history [17]. As

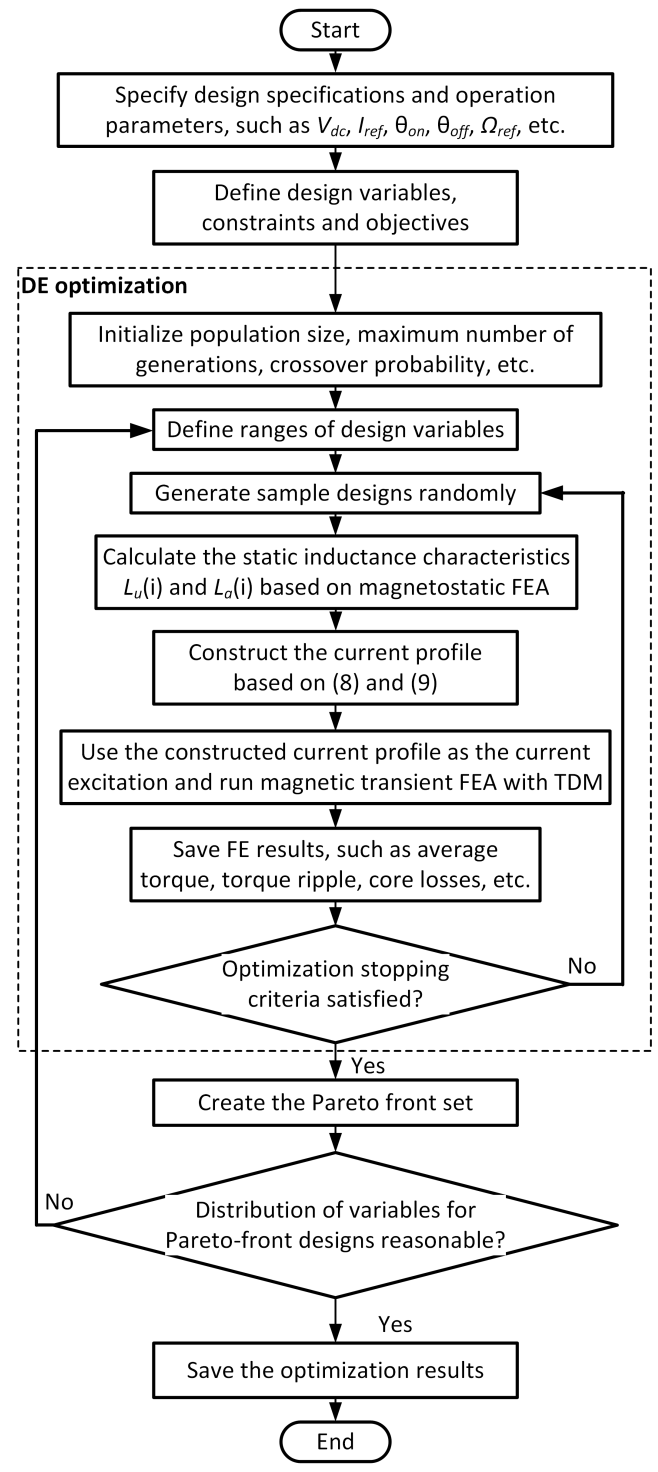

Fig. 6. Flow chart of the proposed DE-based multiobjective design optimization.

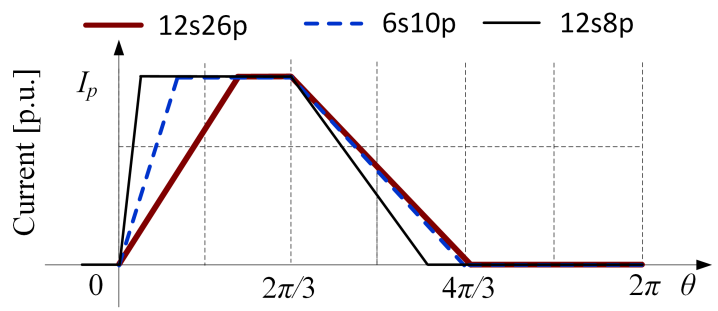

Fig. 7. Current profiles used in the optimization.

the geometric parameters vary over the specified ranges, the electromagnetic torque will change as well. To ensure all the designs produce the same target torque, and have the same thermal performance, the stack length is modified from design to design and the current density in conductors are keep constant at $4 \mathrm{~A} / \mathrm{mm}^{2}$.

\section{OPTIMIZATION RESULTS AND DISCUSSION}

\section{A. Mass and Loss}

The optimization results for mass and loss are shown in Fig. 9. The distribution of evaluated designs in the loss-mass plane 


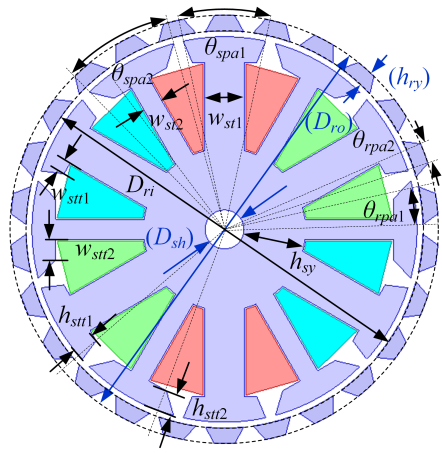

(a)

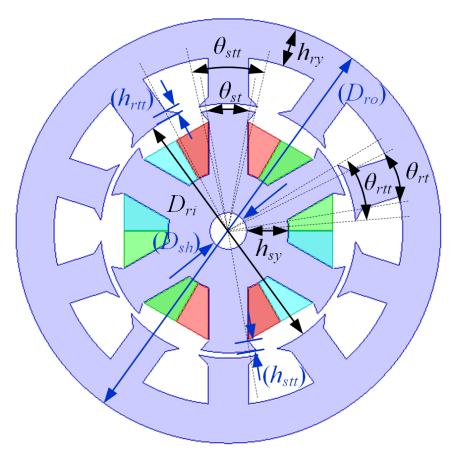

(b)

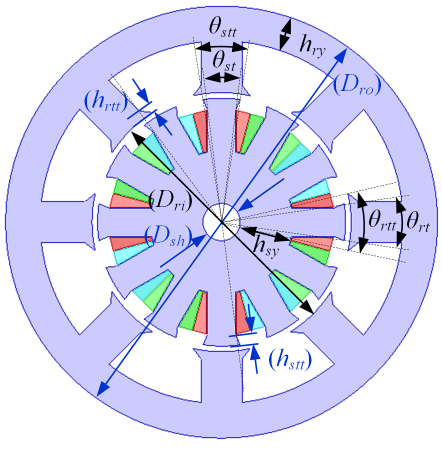

(c)

Fig. 8. Geometric design variables used in the parametric models for: (a) 12s26p SRM, (b) 6s10p SRM, and (c) 12s8p SRM. Independent variables are shown in black fonts. Those in blue and between parenthesis are constants.

Table II: Independent Design Variables and Their p.u. Ranges.

\begin{tabular}{lcccccc}
\hline $\begin{array}{l}\text { Design } \\
\text { variable }\end{array}$ & $\begin{array}{c}12 \mathrm{~s} 26 \\
\text { Range }\end{array}$ & Ref. & $\begin{array}{c}12 \mathrm{~s} 8 \mathrm{p} \\
\text { Range }\end{array}$ & Ref. & $\begin{array}{c}6 s 10 \mathrm{p} \\
\text { Range }\end{array}$ & Ref. \\
\hline$k_{s}$ & {$[0.85,0.92]$} & 0.85 & {$[0.76,0.85]$} & 0.80 & {$[0.76,0.85]$} & 0.80 \\
$k_{s t}$ & - & - & {$[0.92,1.00]$} & 0.96 & {$[0.36,0.54]$} & 0.96 \\
$k_{s t t}$ & - & - & {$[0.80,1.20]$} & 1.00 & {$[0.80,1.20]$} & 1.00 \\
$k_{s y}$ & - & - & {$[0.45,0.62]$} & 0.54 & {$[0.45,0.62]$} & 0.54 \\
$k_{r y}$ & - & - & {$[0.48,0.72]$} & 0.60 & {$[0.48,0.72]$} & 0.60 \\
$k_{r t}$ & - & - & {$[0.31,0.47]$} & 0.39 & {$[0.36,0.54]$} & 0.45 \\
$k_{r t t}$ & - & - & {$[0.31,0.47]$} & 0.39 & {$[0.36,0.54]$} & 0.45 \\
$k_{s p a}$ & {$[0.90,0.95]$} & 0.90 & - & - & - & - \\
$k_{s 1}$ & {$[0.18,0.22]$} & 0.21 & - & - & - & - \\
$k_{s 2}$ & {$[0.09,0.15]$} & 0.13 & - & - & - & - \\
$k_{t i p 1}$ & {$[0.07,0.14]$} & 0.10 & - & - & - & - \\
$k_{t i p 2}$ & {$[0.12,0.14]$} & 0.12 & - & - & - & - \\
$k_{w t p 1}$ & {$[0.04,0.06]$} & 0.04 & - & - & - & - \\
$k_{w t p 2}$ & {$[0.04,0.07]$} & 0.04 & - & - & - & - \\
$k_{b y}$ & {$[0.30,0.60]$} & 0.32 & - & - & - & - \\
$k_{r p a 1}$ & {$[0.70,0.95]$} & 0.85 & - & - & - & - \\
$k_{r p a 2}$ & {$[0.20,0.50]$} & 0.32 & - & - & - & - \\
\hline
\end{tabular}

shows that in order to produce the target torque, the $12 \mathrm{~s} 26 \mathrm{p}$ SRM, generally, requires much smaller mass and incurs lower losses. Some of the 6s10p Pareto-front designs can achieve nearly the same minimum loss compared with the 12s26p SRMs, but the total active mass has to be increased. The $12 \mathrm{~s} 8 \mathrm{p}$ designs have the highest loss and the minimum weight is still about $30 \%$ more than the $12 \mathrm{~s} 26 \mathrm{p}$ counterpart. The lightest designs, which are of more interest to reduce the total unsprung mass of the vehicle, are visualized in Fig. 10, whose details are tabulated in Table III.

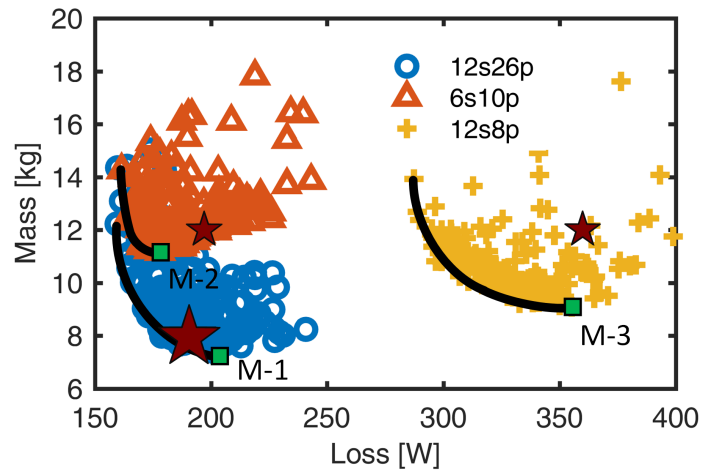

Fig. 9. Mass and loss for the studied designs of the three machine topologies. The large star marks the reference prototype design and smaller stars identify the other reference designs. The designs selected for further discussion are marked by squares.

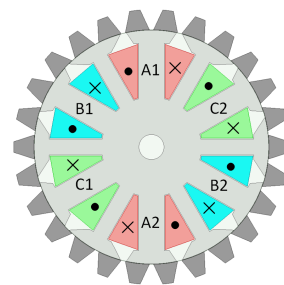

(a)

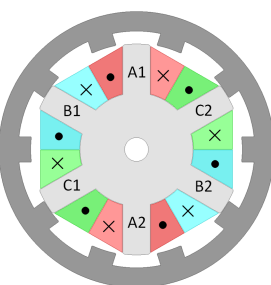

(b)

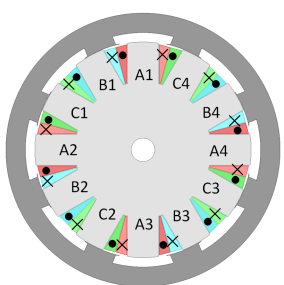

(c)
Fig. 10. Cross sections of the selected Pareto-front designs with the lowest total mass. (a) 12s26p M-1, (b) 6s10p M-2, and (c) 12s8p M-3.

The three selected designs have nearly the same converter VA rating. M-1 shows better performance in terms of the specific torque/power and torque ripple. M-2 has the highest electromagnetic efficiency and goodness factor, but the lowest torque density and specific torque due to the large stack length and end coil size. M-3 has the largest torque/power density because of the small end coil but the electromagnetic efficiency is greatly reduced. The $1.5 \mathrm{~kW}$ prototype was run with a reduced current to produce $18 \mathrm{Nm}$ at $600 \mathrm{rpm}$ for the purpose of comparison.

\section{B. Torque ripple}

The torque ripple has been included in Fig. 11. Since the torque ripple is not one of the optimization objectives, the torque ripple of Pareto-front designs shows some diversity.

Table III: Performance comparison of the lightest designs identified in Fig. 9 and shown in Fig. 10. The stack length is modified to obtain the target torque $18 \mathrm{Nm}$ at $600 \mathrm{rpm}$, and the current density is maintained at $4 \mathrm{~A} / \mathrm{mm}^{2}$.

\begin{tabular}{lrrrr}
\hline Design & Prototype & M-1 & M-2 & M-3 \\
\hline Lamination steel & M27-29G & & M19-24G & \\
Stack length (mm) & 40.0 & 26.3 & 37.0 & 30.9 \\
Volume (L) & 4.3 & 3.3 & 4.0 & 2.4 \\
Mass of steel (kg) & 4.5 & 4.8 & 7.2 & 7.0 \\
Mass of copper (kg) & 3.2 & 2.0 & 4.0 & 2.1 \\
Total mass (kg) & 7.7 & 6.8 & 11.2 & 9.1 \\
Core loss (W) & 31.3 & 36.4 & 41.2 & 31.2 \\
Copper loss (W) & 117.3 & 165.6 & 136.8 & 324.0 \\
EM efficiency (\%) & 88.3 & 84.8 & 86.4 & 76.1 \\
Converter VA rating (kVA) & 4.3 & 3.9 & 3.9 & 4.1 \\
Torque ripple (\%) & 51.4 & 19.4 & 48.3 & 77.4 \\
Torque density (Nm/L) & 4.2 & 5.5 & 4.5 & 7.5 \\
Power density (kW/L) & 0.26 & 0.34 & 0.28 & 0.47 \\
Specific torque (Nm/kg) & 2.3 & 2.6 & 1.6 & 2.0 \\
Specific power (kW/kg) & 0.14 & 0.16 & 0.1 & 0.12 \\
Goodness factor (Nm/ $\sqrt{W}$ ) & 1.48 & 1.27 & 1.35 & 0.96 \\
\hline
\end{tabular}




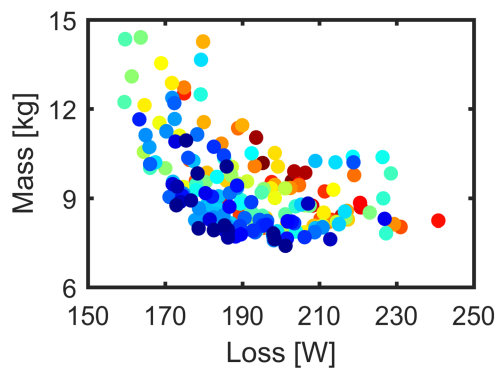

(a)

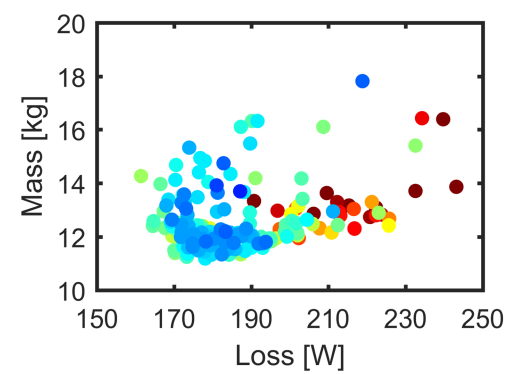

(b)

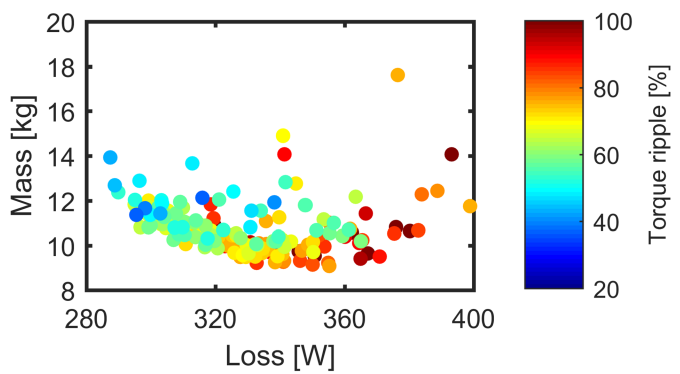

(c)

Fig. 11. The variation of mass versus loss together with torque ripple indicated on a color scale for: (a) 12s26p SRM, (b) 6s10p SRM, and (c) 12s8p SRM.

Most of the Pareto-front designs of 12s26p SRM have relatively lower torque ripple $(20 \%-40 \%)$, which is lower than those of 6s10p and 12s8p SRMs. It is also shown that designs close to the Pareto fronts naturally have relatively low torque ripple compared with other regions in the design space. Further reduction of the torque ripple needs to include the turnon angle and turn-off angle (or dwell angle) as independent variables, and involve sophisticated control methods in the optimization process. Commonly used methods for reducing the torque ripple include current profiling [29], the use of an increased number of phase [30], etc. It may be noted that these methods are also applicable to the machine topologies studied in this paper.

\section{Radial Force and Consideration of Mechanical Aspects}

Compared with the 6s10p and 12s8p SRMs, the 12s26p topology needs additional rotor frame to hold the segments and provide enough stiffness to prevent unacceptable deformations caused by radial forces. The radial magnetic force density distributions of M-1, M-2 and M-3 along the rotor circumferential are calculated from the airgap flux density waveforms and compared at the instant of time when the peak radial force occurs, as shown in Fig. 12. It can be seen that the 12s26p design has the lowest peak radial force density, which may be attributed to the large number of rotor poles and short magnetic flux paths. The relatively low radial force density is expected to simplify the mechanical design of the rotor frame.

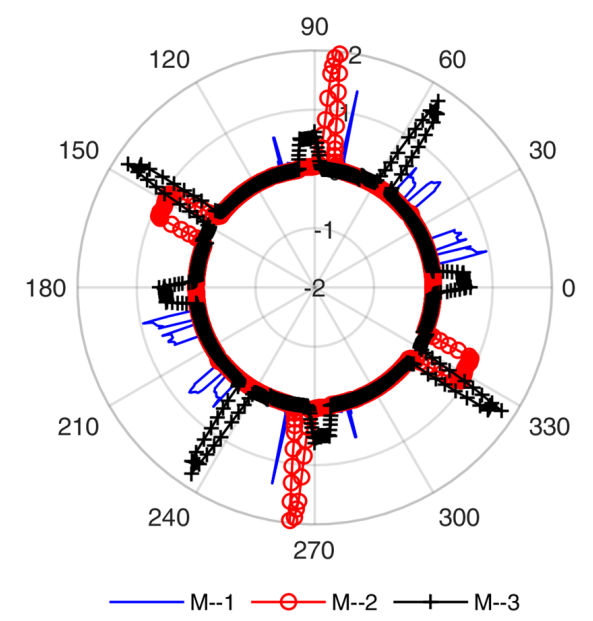

Fig. 12. Radial force density distributions in $\mathrm{Nm} / \mathrm{mm}^{2}$ of $\mathrm{M}-1, \mathrm{M}-2$ and $\mathrm{M}-3$.

\section{Power Factor and VA Rating}

Both the voltage and current waveforms of SRMs are nonsinusoidal, so the power factor has to be calculated using the definition for non-sinusoidal systems, which is a figure of merit that measures how efficiently energy is transmitted and always lies between 0 and 1 [31]. Such a definition is consistent with the power factor used in sinusoidal systems and thus suitable for the comparison between SRMs and conventional ac machines based on general power or torque equations [32]. The power factor is less straightforward than the VA rating in sizing converters for SRMs [18]. The converter VA rating, therefore, instead of the power factor, is calculated for this study.

The converter VA rating at the rated operating point is plotted against the saliency ratio, as shown in Fig. 13. It is seen that all the manifestations of the 12s8p SRM have a higher saliency ratio than the other two topologies. It is also noted that, for each topology, there is an inverse correlation between the converter VA rating and the saliency ratio. In addition, the 12s26p and 6s10p SRMs generally have lower saliency ratio and higher VA rating requirement than $12 \mathrm{~s} 8 \mathrm{p}$ designs.

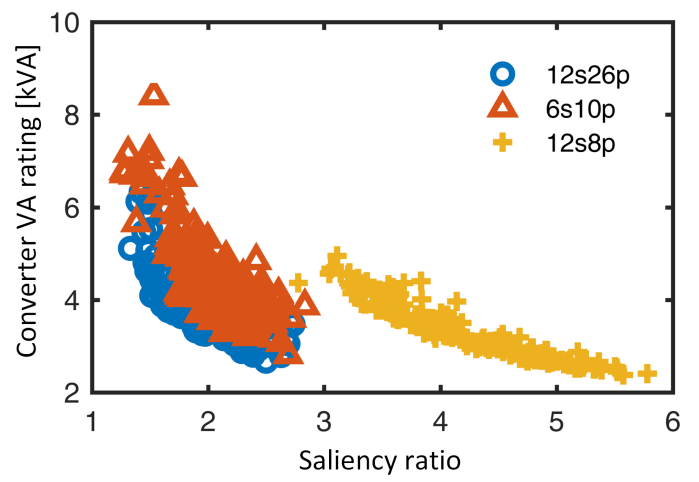

Fig. 13. The converter VA rating versus the saliency ratio for all evaluated designs. For a specific SRM topology, the converter VA rating approximately varies inversely with the saliency ratio.

\section{E. Experimental Results}

The current work expands on a previously reported experimental study for a prototype SRM with a 12 slot stator and a modular/segmented rotor with 26 poles [20] with new insights and results provided, and provides additional results and new technical insights. This prototype SRM was employed both for establishing an experimental validation basis for the 


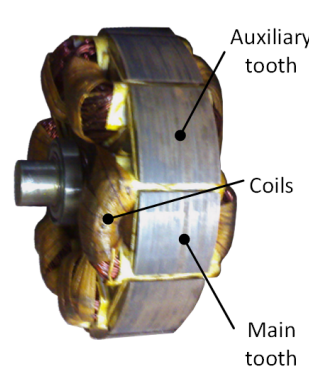

(a)

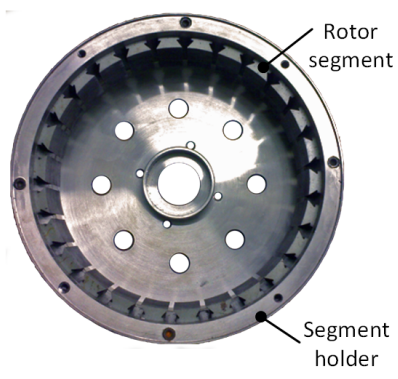

(b)

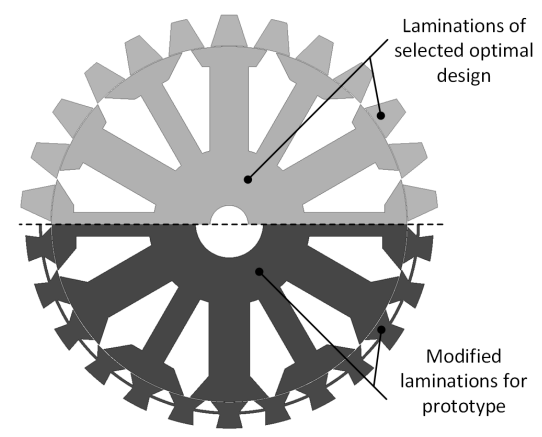

(c)

Fig. 14. Segmented SRM prototype: (a) stator with coils, (b) rotor with module/segment holder, (c) comparison between laminations of the selected optimal design and the prototype. The rotor laminations include dovetails and bridges to simplify the manufacturing process.

electromagnetic field FEA of the type employed for the study of hundreds of candidate designs, as well as an initial reference for the optimization and for the ranges of the design space considered.

The stator and rotor of the prototype SRM are shown in Fig. 14 in a new perspective, together with a cross section of the laminated core, clearly illustrating the rotor construction with ferromagnetic independent modules. The rotor laminations for the actual prototype, which included a dovetail profile, were produced through a wire cutting process with inter-module bridges, which were then machined off before attaching the core modules to a frame made of non-magnetic stainless steel. The total outer diameter and airgap length of the prototype and of the previously selected design M1 are the same with the values listed in I. The stack length of the prototype machine is $40 \mathrm{~mm}$ and the total axial length is $102 \mathrm{~mm}$ taking into account the end coils. The lamination steel material used is M27-29G for both the stator and rotor. The stator coils were hand wound with an equivalent slot fill factor of 0.33 .

The optimization study, previously discussed in the paper, included FEA of hundreds of SRMs and yielded a Pareto font, i.e. a collection of best compromise designs that is representative of the tradeoffs between loss and mass. The location of the prototype, operating at $18 \mathrm{Nm}$ and $600 \mathrm{rpm}$, in the loss-mass plane shown in Fig. 9. is denoted by the largest star. For all practical engineering purposes, especially when considering the inherent differences arising due to manufacturing variations, combined computational errors and measurement uncertainties, the prototype lies on the Pareto front in a region of relatively higher loss and lower mass.

The inductances at various rotor positions shown in Fig. 15 were obtained by measuring the time constant with phase A winding connected in series with an external resistor and supplied by a signal generator. A small value $1.25 \mathrm{mH}$ is considered as the end winding leakage inductance and subtracted from the measured waveform. It is shown that the unsaturated inductance agrees well with that predicted from 2D FEA.

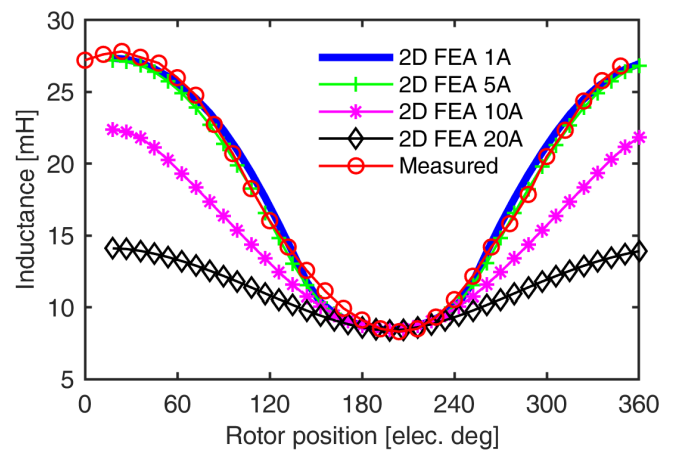

Fig. 15. Comparison of simulated and measured inductance waveforms.

The static torque with only one phase excited by different dc currents was measured at various rotor positions. The measured peak static torque at different currents is plotted in Fig. 16, and shows good agreement with the 2D FFA predictions.

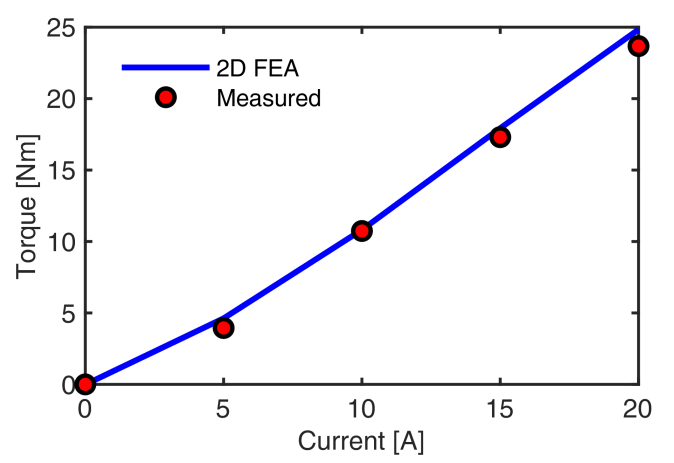

Fig. 16. Comparison of simulated and measured peak values of static torque at different phase currents.

The loss breakdown at $13 \mathrm{Nm}$ and various speeds is shown in Fig. 17. With the increase of the rotor speed, the core losses increase accordingly but the copper loss is the same. The difference between the FEA predicted and measured losses is mainly caused by the mechanical loss, which is not considered in the prediction.

\section{CONCLUSION}

The paper introduces a design method for switched reluctance machines (SRMs) that combines a differential evolutionbased multi-objective optimization technique with fast $2 \mathrm{D}$ FEA based on pre-determined current profile estimations, which consider the power electronic drive controls and result in a substantial reduction of the computational effort, as compared with conventional approaches. The new method 


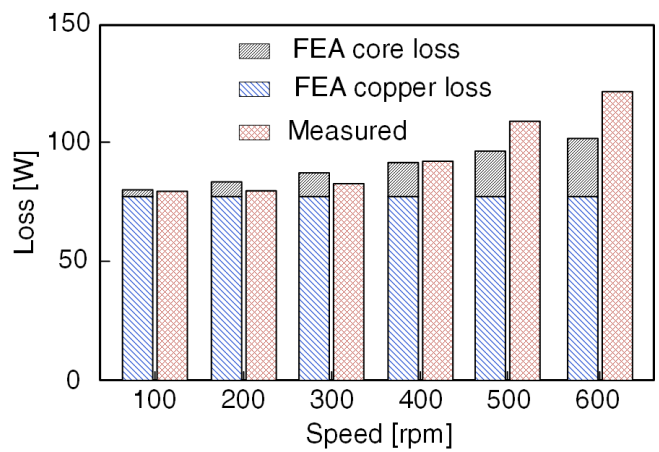

Fig. 17. Comparison of simulated and measured losses at $13 \mathrm{Nm}$ and various speeds.

is supporting another contribution of the paper, which is represented by systematic optimal design comparative studies for three outer-rotor motor topologies for in-wheel directdrive applications. The two objectives considered are mass and losses and the hundreds of SRMs analyzed yield a Pareto front of best compromise designs.

The studies reported include an innovative SRM topology with a modular and segmented rotor for which a prototype was built and tested. The optimization yielded a comprehensive Pareto front that includes the best compromise designs for which improvement can be achieved only by trading off the two objectives of mass and loss. The Pareto spans a relatively large performance space with max to min ranges of approx. 1.25 and 1.7 for losses and mass, respectively. For all practical engineering purposes, the prototype SRM discussed in the paper lays on the Pareto in the more cost competitive higher-loss lower-mass region and additionally provides useful technical insights.

It is also shown that modular and segmented rotor SRMs are superior, in terms of specific torque and efficiency, to the conventional configuration motors considered. Furthermore, the large scale studies with hundreds of candidate designs indicate that SRMs with higher number of rotor poles than stator teeth have higher converter volt-ampere rating.

\section{ACKNOWLEDGMENT}

The support of ANSYS Inc. and University of Kentucky, the L. Stanley Pigman endowment and the SPARK program, is gratefully acknowledged.

\section{REFERENCES}

[1] Z. Q. Zhu and D. Howe, "Electrical machines and drives for electric, hybrid, and fuel cell vehicles," Proc. IEEE, vol. 95, no. 4, pp. 746-765, Apr. 2007.

[2] M. Krishnamurthy, C. S. Edrington, A. Emadi, P. Asadi, M. Ehsani, and B. Fahimi, "Making the case for applications of switched reluctance motor technology in automotive products," IEEE Trans. Power Electron., vol. 21, no. 3, pp. 659-675, May 2006.

[3] K. Kiyota, T. Kakishima, and A. Chiba, "Comparison of test result and design stage prediction of switched reluctance motor competitive with $60-\mathrm{kW}$ rare-earth PM motor," IEEE Trans. Ind. Electron., vol. 61, no. 10, pp. 5712-5721, Oct. 2014.

[4] M. Frajnkovic, S. Omerovic, U. Rozic, J. Kern, R. Connes, and K. Rener, et al., "Structural integrity of in-wheel motors," in SAE Technical Paper. SAE International, Sep. 2018.
[5] T. J. E. Miller, "Optimal design of switched reluctance motors," IEEE Trans. Ind. Electron., vol. 49, no. 1, pp. 15-27, Feb. 2002.

[6] B. Mirzaeian, M. Moallem, V. Tahani, and C. Lucas, "Multiobjective optimization method based on a genetic algorithm for switched reluctance motor design," IEEE Trans. Magn., vol. 38, no. 3, pp. 1524-1527, May 2002.

[7] C. Ma and L. Qu, "Multiobjective optimization of switched reluctance motors based on design of experiments and particle swarm optimization," IEEE Trans. Energy Convers., vol. 30, no. 3, pp. 1144-1153, Sep. 2015.

[8] S. Brisset and P. Brochet, "Optimization of switched reluctance motors using deterministic methods with static and dynamic finite element simulations," IEEE Trans. Magn., vol. 34, no. 5, pp. 2853-2856, Sep. 1998.

[9] E. Öksüztepe, "In-wheel switched reluctance motor design for electric vehicles by using a Pareto-based multiobjective differential evolution algorithm," IEEE Trans. Veh. Technol., vol. 66, no. 6, pp. 4706-4715, Jun. 2017.

[10] Z. Yang, F. Shang, I. P. Brown, and M. Krishnamurthy, "Comparative study of interior permanent magnet, induction, and switched reluctance motor drives for EV and HEV applications," IEEE Trans. Transp. Electrific., vol. 1, no. 3, pp. 245-254, Oct. 2015.

[11] J. W. Jiang, B. Bilgin, B. Howey, and A. Emadi, "Design optimization of switched reluctance machine using genetic algorithm," in Proc. IEEE Int. Electr. Mach. Drives Conf. (IEMDC), May 2015, pp. 1671-1677.

[12] V. Rallabandi, J. Wu, P. Zhou, D. G. Dorrell, and D. M. Ionel, "Optimal design of a switched reluctance motor with magnetically disconnected rotor modules using a design of experiments differential evolution FEA-based method,' IEEE Trans. Magn., vol. 54, no. 11, pp. 1-5, Nov. 2018.

[13] J. Lee, J. H. Seo, and N. Kikuchi, "Topology optimization of switched reluctance motors for the desired torque profile," Struct. Multidiscip. Optim., vol. 42, no. 5, pp. 783-796, Nov. 2010.

[14] J. D. Widmer, R. Martin, and B. C. Mecrow, "Optimization of an $80-\mathrm{kW}$ segmental rotor switched reluctance machine for automotive traction," IEEE Trans. Ind. Appl., vol. 51, no. 4, pp. 2990-2999, Jul. 2015.

[15] V. Rallabandi, J. Wu, A. M. Cramer, D. M. Ionel, and P. Zhou, "Optimal design of outer rotor switched reluctance machines for direct drive rim applications," in Proc. IEEE Energy Convers. Congr. Expo. (ECCE), Sep. 2018, pp. 6104-6109.

[16] M. Rosu, P. Zhou, D. Lin, D. M. Ionel, M. Popescu, F. Blaabjerg, V. Rallabandi, and D. Staton, Multiphysics Simulation by Design for Electrical Machines, Power Electronics and Drives. Wiley-IEEE Press, 2017.

[17] P. Zhou, B. He, C. Lu, D. Lin, and N. Chen, "Transient simulation of electrical machines using time decomposition method," in Proc. IEEE Int. Electr. Mach. Drives Conf. (IEMDC), 2017, pp. 1-6.

[18] T. J. E. Miller, "Converter volt-ampere requirements of the switched reluctance motor drive," IEEE Trans. Ind. Appl., vol. IA-21, no. 5, pp. 1136-1144, Sep. 1985.

[19] P. C. Desai, M. Krishnamurthy, N. Schofield, and A. Emadi, "Novel switched reluctance machine configuration with higher number of rotor poles than stator poles: Concept to implementation," IEEE Trans. Ind. Electron., vol. 57, no. 2, pp. 649-659, Feb. 2010.

[20] S. P. Nikam, V. Rallabandi, and B. G. Fernandes, "A hightorque-density permanent-magnet free motor for in-wheel electric vehicle application," IEEE Trans. Ind. Appl., vol. 48, no. 6, pp. 2287-2295, Nov. 2012.

[21] J. Zhu, K. W. E. Cheng, X. Xue, and Y. Zou, "Design of a new enhanced torque in-wheel switched reluctance motor with divided teeth for electric vehicles," IEEE Trans. Magn., vol. 53, no. 11, pp. 1-4, Nov. 2017. 
[22] L. Szabo and M. Ruba, "Segmental stator switched reluctance machine for safety-critical applications," IEEE Trans. Ind. Appl., vol. 48, no. 6, pp. 2223-2229, Nov. 2012.

[23] X. Liang, G. Li, J. Ojeda, M. Gabsi, and Z. Ren, "Comparative study of classical and mutually coupled switched reluctance motors using multiphysics finite-element modeling," IEEE Trans. Ind. Electron., vol. 61, no. 9, pp. 5066-5074, Sep. 2014.

[24] J. Dong, B. Howey, B. Danen, J. Lin, J. W. Jiang, and B. Bilgin, et al., "Advanced dynamic modeling of three-phase mutually coupled switched reluctance machine," IEEE Trans. Energy Convers., vol. 33, no. 1, pp. 146-154, Mar. 2018.

[25] V. Rallabandi and B. G. Fernandes, "Design methodology for high-performance segmented rotor switched reluctance motors," IEEE Trans. Energy Convers., vol. 30, no. 1, pp. 11-21, Mar. 2015.

[26] X. Sun, K. Diao, G. Lei, Y. Guo, and J. Zhu, "Study on segmented-rotor switched reluctance motors with different rotor pole numbers for BSG system of hybrid electric vehicles," IEEE Trans. Veh. Technol., vol. 68, no. 6, pp. 5537-5547, Jun. 2019.

[27] T. Husain, A. Elrayyah, Y. Sozer, and I. Husain, "Unified control for switched reluctance motors for wide speed operation," IEEE Trans. Ind. Electron., vol. 66, no. 5, pp. 3401-3411, May 2019.

[28] Z. Q. Zhu, B. Lee, L. Huang, and W. Chu, "Contribution of current harmonics to average torque and torque ripple in switched reluctance machines," IEEE Trans. Magn., vol. 53, no. 3, pp. 1-9, Mar. 2017.

[29] R. Mikail, I. Husain, Y. Sozer, M. S. Islam, and T. Sebastian, "Torque-ripple minimization of switched reluctance machines through current profiling," IEEE Trans. Ind. Appl., vol. 49, no. 3, pp. 1258-1267, May 2013.

[30] X. Deng, B. Mecrow, H. Wu, and R. Martin, "Design and development of low torque ripple variable-speed drive system with six-phase switched reluctance motors," IEEE Trans. Energy Convers., vol. 33, no. 1, pp. 420-429, 2018.

[31] R. W. Erickson and D. Maksimovic, Fundamentals of Power Electronics, 2nd ed. New York: Kluwer Academic Publishers, 2004.

[32] A. V. Radun, "Design considerations for the switched reluctance motor," IEEE Trans. Ind. Appl., vol. 31, no. 5, pp. 1079-1087, Sep. 1995

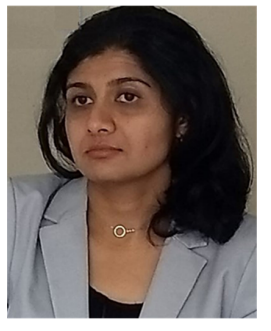

Vandana Rallabandi (M'17-SM'19) is a Lea Engineer at GE Research in Niskayuna, NY, USA. Previously, she was a Postdoctoral Researcher with the SPARK Lab, University of Kentucky, Lexington, KY, USA, and a Research Engineer with the GE Research Center, Bangalore, India. Her research interests include electric machines, power electronics drives, renewable energy devices and systems, energy storage, and power systems. She received the masters and Ph.D. degrees from the Indian Institute of Technology Bombay, Mumbai, India.

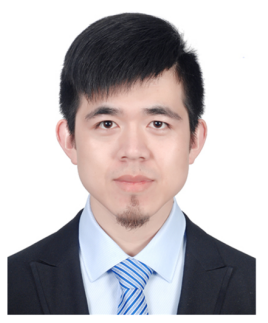

Peng Han (S'12-M'17-SM'20) received the B.Sc. and $\mathrm{Ph} . \mathrm{D}$. degrees in Electrical Engineering from the School of Electrical Engineering, Southeast University, Nanjing, China, in 2012 and 2017, respectively.

From November 2014 to November 2015, he was a joint Ph.D. student funded by China Scholarship Council with the Department of Energy Technology, Aalborg University, Aalborg, Denmark, where he focused on the brushless doubly-fed machines for wind energy conversion and high power drive. He is currently a postdoctoral researcher with the SPARK Laboratory, Department of Electrical and Computer Engineering, University of Kentucky. His current research interests include electric machines, power electronics and renewable energy.

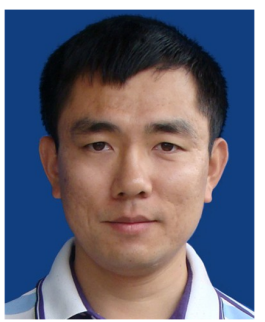

Jie Wu (M'17) received the M.Eng. degree in electrical engineering from the Hubei University of Technology, Wuhan, China, in 2005, and the Ph.D. degree from the VŠB-Technical University of Ostrava, Czech Republic, in 2012. He previously worked with the Hubei University of Technology. Since 2017, he has been a Visiting Professor with the Department of Electrical and Computer Engineering, University of Kentucky, Lexington, KY, USA. He is currently an Assistant Professor with the Zhengzhou University of Light Industry, Zhengzhou, China. He contributed to the AC flux control technology in hybrid excitation machine. His expertise in electrical power engineering includes electrical machines, power electronic drives, and simultaneous wireless information and power transfer.

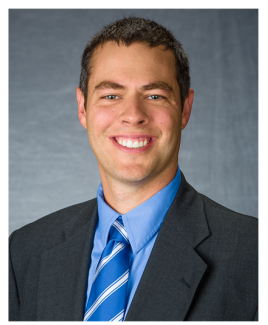

Aaron M. Cramer (S'02-M'07-SM'13) received the B.S. degree (summa cum laude) in electrical engineering from the University of Kentucky, Lexington, KY, USA, in 2003, and the Ph.D. degree from Purdue University, West Lafayette, IN, USA, in 2007. From 2007 to 2010, he was a Senior Engineer with PC Krause and Associates, West Lafayette, IN, USA. He joined the University of Kentucky in 2010, where he is currently an Associate Professor. His research interests include simulation, control, and optimization of power and energy systems. Dr. Cramer was a recipient of the ONR Young Investigator Program Award in 2015. He serves as an Editor for the IEEE TRANSACTIONS ON ENERGY CONVERSION.

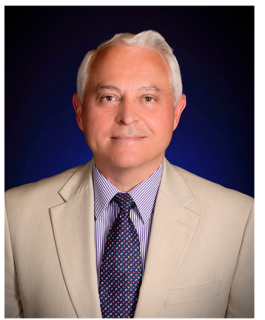

Dan M. Ionel (M'91-SM'01-F'13) is Professor of Electrical Engineering and the L. Stanley Pigman Chair in Power at the University of Kentucky, Lexington, KY, where he is also the Director of the Power and Energy Institute of Kentucky (PEIK) and of the SPARK Laboratory. He previously worked in industry, most recently as Chief Engineer for Regal Beloit Corp., Grafton, WI, USA, and, before that, as the Chief Scientist for Vestas Wind Turbines. Concurrently, he was also a Visiting and Research Professor with the University of Wisconsin and Marquette University in Milwaukee, WI. Dr. Ionel contributed to technology developments with long lasting industrial impact, holds more than 35 patents, published more than 200 papers, and co-authored 3 books. His research has been supported directly by industry, and by NSF, NIST, DOE, and NASA.

$\mathrm{He}$ received the M.Eng. and Ph.D. degrees in electrical engineering from the Polytechnic University of Bucharest, Bucharest, Romania. His doctoral program included a Leverhulme Visiting Fellowship with the University of Bath, Bath, U.K., and later he was a Postdoctoral Researcher with the SPEED Laboratory, University of Glasgow, Glasgow, U.K

Dr. Ionel is an IEEE Fellow and a recipient of the IEEE PES Veinott Award. He was the Inaugural Chair of the IEEE Industry Applications Society Renewable and Sustainable Energy Conversion Systems Committee, an Editor for the IEEE Transactions on Sustainable Energy, the Chair of the IEEE PES MSC and of the IEEE WG 1812, the Technical Program Chair of 2015 IEEE ECCCE and the General Chair of the 2017 IEEE IEMDC. He is the Editor-inChief of the Electric Power Components and Systems Journal, and the Chair of the Steering Committee for the IEEE IEMDC Conferences. 


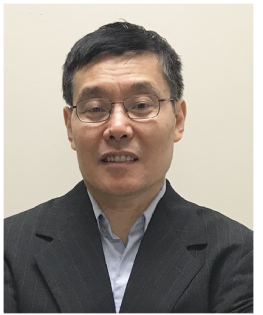

Ping Zhou (M'95-SM'07-F'16) is a director of research and development in ANSYS, leading the research and development of low-frequency products. He has hold 5 patents, published more than 90 papers in the area of electromagnetic numerical simulation and material modeling, especially for electrical machine applications.

Dr. Zhou received his Ph.D. degree from Memorial University of Newfoundland, Canada, in 1994 after he was a visiting scholar from 1989 to 1990 in the same university. From 1977 to 1989, he worked in Shanghai University of Technology (current Shanghai University) as a lecture. In 1994, he joined Ansoft Corporation (which was acquired by ANSYS Inc in 2008) in USA and he is the original author of Maxwell products. He serves as paper reviewer for IEEE Trans. Magnetics, IEEE Trans. Industry Application, and IEEE Trans. Energy Conversion. He also serves as technical program co-chair of IEMDC2017 and the organizing committee cochairs of CEFC 2018. 